\title{
Political conservation, or how to prevent institutional decay
}

Beckstein, Martin

\begin{abstract}
Sometimes established institutions aren't perfect but cannot be replaced with better solutions. As technological, economic, ecological and other developments might indirectly further impair these imperfect institutions, non-change becomes normatively desirable and a practical challenge for legislators. In contrast to the progressive task of improving the established order, the task of preventing institutional achievements from being lost has been largely neglected by political theorists. To fill this lacuna, the article explores conservation as a mode of political action. It specifies the conditions under which it is reasonable to oppose institutional innovation in politics in order to keep things as they are and develops a formal solution to Edmund Burke's 'conservation paradox' in which existing arrangements can only stay the same if they are changed. The solution construes political conservation as renovative reformism that adapts institutional structures, cultures or mechanisms to changing circumstances in order to prevent indirect transformations of institutional mandates.
\end{abstract}

DOI: https://doi.org/10.1111/1467-8675.12403

Posted at the Zurich Open Repository and Archive, University of Zurich

ZORA URL: https://doi.org/10.5167/uzh-158514

Journal Article

Accepted Version

Originally published at:

Beckstein, Martin (2019). Political conservation, or how to prevent institutional decay. Constellations, 26(4):623-637.

DOI: https://doi.org/10.1111/1467-8675.12403 


\title{
Political Conservation, or How to Prevent Institutional Decay
}

[The final, definitive version of this paper will be published in Constellations (https://onlinelibrary.wiley.com/journal/14678675) by Wiley Blackwell, All rights reserved. (C) Martin Beckstein]

\begin{abstract}
Sometimes established institutions aren't perfect but cannot be replaced with better solutions. In situations of this kind, forestalling decay, not forcing progress, is the order of the day. But what needs to be done to prevent change for the worse? Must anything be done at all? To help answering these questions, the article explores conservation as a mode of political action. It argues that securing the choice to retain a comparatively favored institution becomes a practical challenge for legislators when technological, economic, ecological and other external developments threaten to turn its effective function away from which we value it. To cope with the task, legislators must resolve Edmund Burke's 'conservation paradox' in which existing arrangements can only stay the same if they are changed. The article provides a formal solution by construing political conservation as renovative reformism that adapts institutional structures, cultures or mechanisms to changing circumstances in order to prevent the accidental transformation of institutional mandates, and points out why political disputes may arise even among persons who are equally interested in leaving things as they are.
\end{abstract}

\section{Keywords}

Burke, change, conservation, institutions, reform

\section{Introduction}

An important objective of political theory is to establish principles and generalities that provide normative guidance for political action. The question — what is the best possible thing to do in the current situation? - often appropriately motivates the inquiry into possibilities of improving the present state 
of affairs. Scholars will accordingly try to identify elements of the existing social order that fail to realize normative principles such as liberty, equality or justice and develop institutional alternatives. A prominent example of such scholarship is the Rawlsian rejection of welfare state capitalism in favor of a property-owning democracy or market socialism (see e.g. O'Neill and Williamson, 2012). However, occasionally the best thing to do in politics is to leave things as they are. In situations of this kind, nonchange is desirable even though there might be room for improvement; forestalling decay, not forcing progress, is the order of the day. What resources has political theory to offer to practitioners of politics in such cases? Are there any principles or generalities that provide normative guidance when the task consists in preventing institutional achievements from being lost? In contrast to the task of realizing change for the better, it appears, the task of averting change for the worse has not been sufficiently explored.

There are several possible explanations for why political conservation has slipped the attention of scholars whether in the liberal, socialist or conservative traditions. One that will mainly occupy us here is a propensity across these traditions to expect that the institutional status quo persists unchanged unless legislators implement a scheme to change it. We will see later that this expectation does not qualify as valid reasoning that provides reliable guidance for political practice. But of course there are other explanations, too. Occasionally an emancipatory self-understanding may have lead scholars to assume that there is always room for improvement. Huntington (1965, p. 393; see also Smith, 2016, p. 350) once noted in this sense that a strong commitment to the theory of progress makes political decay an unthinkable concept. Furthermore, in some schools of political theory conservation simply doesn't occur as a task. 'Ethics first' approaches (Williams, 2005, pp. 1-3) promise to provide normative guidance for political practice independently of the currently established order. Finding out what the best possible thing to do requires a comparative understanding of better-ness, which we can only reach by weighing the desirability and feasibility of conceivable institutional alternatives against the normative quality and stability of existing arrangements. Yet 'ethics first' theorists tend to bracket the comparison out of their analysis, suggesting that this is the point where political theorists and political scientists divide labor. Furthermore, change for change's sake seems to be ingrained in the nature of democratic systems. They 'encourag[e] both activism and the rhetorical defences that will rationalize such activism' (Brennan and 
Hamlin, 2004, pp. 683-4). Finally, considering the discipline of political theory more generally, the neglect of conservation might also reflect a male-biased apparatus of social analysis. Just as Heidegger (1971, pp. 147-9) implicitly prioritized 'building' (as the world-founding of an active subject) over 'preserving' (as epitomized by agriculture and housework) despite claiming that they are equally important moments of human life (Irigaray, 1992; Young, 1997, ch. VII), so might political theorists tend to suppose that institutional innovation is what really matters in politics. But, as Iris Young (1997, pp. 152) notes after reminding us that for Arendt the quintessential moment of human meaning and individuality is that of founding, 'as soon as the deeds of founding are accomplished, as soon as the heroic work of the artist, the statesman, or planner are recognized and celebrated, a new task comes into play: preservation.'

The literature that operates under the label 'conservatism' is, without a doubt, a viable source of inspiration for the exploration of conservation as a mode of political action but doesn't effectively mitigate the scholarly neglect of this topic as we will see. For many readers this might not come as a real surprise. According to a particularly influential view, conservatism - contrary to what the meaning of the word 'to conserve' suggests - does not oppose institutional change. Although conservatives have often defended certain historical institutions against reformers and revolutionaries, they are not concerned with the conservation of existing institutions as such. Their main focus is instead, as for instance Michael Freeden (1996, esp. 332) has argued, on ways to render institutional change safe. The mode of political action conservatives primarily bank on, accordingly, is progressive action. The main difference to proponents of other emancipatory ideologies is the strategy to rely on gradual or incremental reforms because - compared with ambitious schemes of social engineering — they are likely to be better calculable, less costly, more efficient and reversible. ${ }^{1}$ According to other accounts (e.g. Beckstein 2015; Brennan and Hamlin 2004; 2016a; 2016b; Cohen 2007; 2013; Huntington 1957;

1 See e.g. O’Hara (2016). Concurring with this view, Jerry Z. Muller (1997, p. 7) considers 'historical utilitarianism' to be the common denominator of conservative theories. 
Oakeshott 1991a), conservatism is intrinsically linked with the goal of conservation. ${ }^{2}$ However, the primary concern of conservative theory on this view is on why we might want to keep things as they are (rather than how we can manage to do so). And the conservative classics commonly interrogated to reflect about such reasons such as Burke, (2009) Huntington (1957) or Tomasi di Lampedusa (1970, p. 40) merely provide a rough idea about the practical challenge associated with the goal of realizing nonchange. In short, conservation as a mode of political action has not been a subject of detailed analysis in conservative theory either.

The neglect of conservation as a mode of political action points towards a gap, which to fill is of general interest for scholarship on politics. Yet filling the gap is also a task of practical relevance, moreover one that is particularly urgent to address today. As has often been corroborated since Habermas's (1986) intervention in the 1980s, large segments of Western societies appear to experience an exhaustion of utopian energies. 'We've buried utopia [...], we can't imagine a better world than the one we've got', observes Bregman (2016, back cover), for instance. Fears that institutional achievements (such as the welfare state or representative democracy) could be hollowed out (be it by neoliberals, lobbyists, technocrats or populists; see e.g. Crouch, 2004) are more widespread than hopes for a better realization of principles of justice. Surveys also show that many in the West are pessimistic about the future prospects for the youth. Four of five in the United States question the country's progressive ethos by doubting that their youth will grow up to be better off than they themselves. In France seven out of ten are even more decidedly pessimistic about the future prospects of their children's generation (Ipsos MORI, 2014; see also Taylor, Funk and Craighill, 2006). Ipsos MORI (2017) even attributes the increasing tendency to cherish what we've got a worldwide significance, and lists the 'return to tradition' as the second most important 'global mega trend 2017'. This might be a deplorable development, 'a global epidemic of nostalgia' (Boym 2001, xiv; see also Bauman 2017, 5). We might

2 This paper doesn't need to side with one or the other camp as the main focus is on a general mode of political action rather than an ideology. To indicate this paper's agnosticism concerning the relationship of conservative ideology and the practical task of order maintenance, I will speak of 'political conservation' (rather than, for instance, 'conservative action'). 
well need to reinvigorate progressive thinking and redirect our attention to ways of making the world a better place. At the same time, a democracy ought to be responsive to the actual preferences of citizens. If many people in our countries are more concerned about falling backwards instead of hoping to progress forward, there is good reason to reflect about how we can manage, at least as a political minimum, to avert change for the worse.

To plausibilize the assumption that there can be situations in which legislators ought to desist from replacing imperfect institutions, the article begins with a list of six considerations for opposing institutional change in politics. It suggests that political conservation must be considered a general mode of political action which is relevant independently of specific ideological (especially conservative) commitments (2). It then refutes the view that legislative procedures and revolutions are the only significant threats for the continued existence of established institutions. It argues that institutions may be hollowed out without intentional actor interference because the world changes around them. Strategies of maintaining established institutions must therefore usually take the form of positive action rather than quietism (3). On this basis, readers are introduced to Burke's 'paradox of conservation', according to which existing arrangements must change to stay the same, and a formal solution to this (seeming) paradox is developed. The solution construes political conservation as a kind of renovative reformism that adapts institutional structures, cultures or mechanisms to changing circumstances in order to prevent the accidental transformation of institutional mandates (4). After a brief note about controversies that might arise among people who equally want to leave things as they are, the concluding part spells out implications for normative political theory and provides a version of how political conservation can be an unexpected source of progress (5).

To reduce complexity, the discussion is carried through on the level of legal institutions rather than entire political orders. Moreover, the focus is on (legal) institutions rather than other things that might also embody social capital, such as ways of life or particular buildings. Further insights into the topic could, without a doubt, be gained via concrete and detailed applications rather than brief examples of illustration. This is the price of searching for ways to prevent institutional change in general. 


\section{Why settle for the status quo?}

Legal institutions, such as the freedom of speech, unemployment insurance, marriage, the police or state schools are 'systems of rules governing specific social action in the context of a comprehensive social order' (Ruiter, 2001, p. 71). They are outcomes of politics even though they may often be deeply entrenched in immemorial social customs and tradition. As outcomes of politics, Popper (1972, p. 133) says, legal institutions 'fulfil certain prima facie social functions' (such as teaching or policing) that in turn serve certain 'prima facie social purposes' (such as the propagation of knowledge or protection from violence). With the qualification 'prima facie', Popper makes two stipulations. On one hand, institutions may serve unintended or latent functions in addition to what they are designed to do, for instance, by influencing other institutions in a manner not recognized by us. On the other hand, individuals may run institutions in such a way as to serve their own purposes rather than the designated ones. Officers may accept bribes and thus participate in crime rather than prosecute it, while teachers may propagate personal opinions instead of knowledge (Popper, 1972, p. 134).

When an established institution fails to do what we want them to do, we should explore options to rectify the problem by either replacing or substantially modifying that institution. But to explore options does not yet mean finally to decide to seek replacement or deep modification of the institution in question. At least six distinct types of considerations may lead us to the conclusion that sometimes the best thing to do is to leave things as they are, and for that matter, refrain from changing established institutions or substituting them with conceivable alternatives: lack of alternatives, transition costs, precaution, existence value, lack of feasibility, and democratic authorization.

\subsection{Lack of alternatives}

The most obvious reason for not substantially changing or substituting an existing institution consists in the lack of alternatives. We might not think that some existing institution is objectively flawless: perfectly just, efficient, etc. But any deviation from the status quo is objectionable as long as we are not aware of normatively more desirable alternatives.

\subsection{Transition costs}


Institutional change is not free of charge. It brings material as well as learning costs for those subjected to the institution in question. A re-equilibration of the institutional configuration is necessary if the replaced institution was functionally intertwined with others. Past policy choices, as path dependency theory tells us, may lower the incentives for institutional change up to the point of 'lock-ins' (Pierson, 2000; see also and Brennan and Hamlin, 2016[b], pp. 346 and Aristotle, Politics, II.8; Plato, The Laws, ch. VII). Replacing or substantially changing an existing institution is therefore undesirable unless the value of the envisioned alternative exceeds the value of the existing institution plus transition costs.

\subsection{Precaution $^{3}$}

Another type of reason that partly revolves around transition costs stems from epistemic considerations. Both means and ends in politics are clouded by uncertainty. We cannot know for sure what an objectively perfect institution looks like, and if we think we know, we still cannot be sure to realize it in practice. As we lack a holistic grasp of social life, there is the permanent danger to underestimate the mutual interdependencies among institutions and to miscalculate the future behavior of the individuals that are subjected to them (Berlin, 1990; Burke, 2009, p. 61; Oakeshott, 1996, esp. p. 31; O’Hara, 2011, ch. 2-3; Quinton, 1978). In addition to this, it has been argued that arrangements of the status quo are systematically undervalued, for instance, because they serve as storage systems for accumulated practical knowledge (Kriele, 1979, pp. 42, 49; Oakeshott, 1991c; Quinton, 1978; pp. 16-7). Innovation designed to implement institutional change might therefore negatively affect the functioning of other institutions, not function at all if people react defiantly or bring unintended consequences if they realign their behavior in unexpected ways. ${ }^{4}$ In other words, there is no assurance that the replacement of an existing institution will pay off even if we have taken transition costs into account. Of course, it is also possible that institutional change succeeds without complications and realizes better results than expected. But the uncertainty regarding transition costs and outcomes may well discourage us from

3 For a general critique of the precautionary principle, see Sunstein (2005); for a comparison of the precautionary principle and the (Oakeshott's) disposition to be conservative, see Turner (2010).

4 Hirschman (1991) calls these the jeopardy, futility and perversity theses of reactionary rhetoric. 
seeking change, and what economists call the law of diminishing marginal utility (i.e. the idea that the first piece of chocolate cake gives you greater pleasure than the second and third piece) warrants at least a moderate status-quo orientation in politics: if an innovation is equally likely to increase or decrease the overall value of the institutional order by the same amount, it is rational to oppose the innovation because "the potential welfare losses from moving in the "wrong" direction systematically exceed the potential gains from moving in the "right" direction' (Brennan and Hamlin, 2004, p. 685).

\subsection{Existence value}

A fourth consideration is axiological in nature. It suggests that a specific kind of value resides in arrangements of the status quo because they are part of the status quo. If an arrangement is valuable as such, the idea goes, it also has some 'existence value' over and above its basic value. Institutional change is therefore properly resisted even if the basic value of the conceived alternative exceeds the basic value of the existing institution, as long as the latter's existence value is large enough. Existence value can be based either on a thing's particularity or the relation of individuals to that thing. Current scholarship is interested in existence value primarily because it constitutes a neglected axiological category (Brennan and Hamlin, 2016[a]; Cohen, 2013; Nebel, 2015). Its practical implications might not reach too far. Nevertheless, the fact that people occasionally identify with, and in that sense personally value, existing institutions should not be neglected when weighing pros and cons of institutional change (Wall, 2015, pp. 51, 60). There is, for instance, good egalitarian reason to replace the Queen in the United Kingdom with a president. At the same time, many British citizens have grown fond of the monarchic element. It has become an important part of British collective identity and substantially contributes to social cohesion.

\subsection{Lack of feasibility}

After taking considerations (2.2), (2.3), and (2.4) into account, we might be convinced that better institutional alternatives are actually available in theory, but doubt that they could ever be realized in practice. We would reach the conclusion that desirable institutional alternatives are unfeasible ideals, for instance, because they are construed on the basis of too optimistic assumptions about human nature 
or because they fail to take technological limitations into account, and therefore settle with the status quo.

\subsection{Democratic authorization}

Even if a normatively superior and feasible alternative is available, an imperfect existing institution can still be worthy of conservation if it has been democratically authorized. Unless a formally correct democratic procedure authorizes institutional change, the government and the citizenry ought to feel obliged by the directives of existing institutions and recognize them as the appropriate arrangement. In other words, we have another reason for leaving things as they are if the people of a democracy has de facto authorized an existing institution to govern a particular aspect of its life.

A strategic consideration that combines (2.5) and (2.6) should finally be mentioned here even though it doesn't provide a distinct normative reason for non-change because it seems to be particular relevant for political practice and because it has often motivated conservative thinkers to defend a particular status quo. Suppose that we know what a normatively superior and technically feasible alternative to an existing institution looks like but that we also know that its realization lacks majority appeal and doesn't stand a fair chance of passing the legislative process. Would we nevertheless insist on putting institutional change on the agenda, three scenarios seem to be the likely consequence: (a), we could waste our time. Or (b) we might create more favorable conditions for the desired (and desirable) change in the future. Conversely, however (c), we could give a forum to adverse policies and legislators might end up implementing an institutional arrangement that has majority appeal but that (we think) worsens rather than improves the status quo. Hence, the best thing to do could well be to not bring the issue up in the first place or paint the existing arrangements in rosy colors. Huntington (1957), for instance, argued in this sense that stubborn adherence to the imperfect status quo (USA in the 1950s) constituted the most promising strategy to prevent Soviet socialism (in his view a fundamentally misguided ideology) from making inroads. In a similar vein, Oakeshott (1991a) called for the cultivation of a disposition to be conservative in politics because he believed that too many politicians and fellow citizens (in the 1950s in the UK) were overly ambitious and entrepreneurial. 
In sum, these considerations show the idea that occasionally the best thing to do in politics is to resist institutional innovation. Considerations (2.2), (2.3), and (2.4) indicate that a plausible case can be made for a general status-quo orientation in politics. Surely, this status-quo orientation would have to be a limited disposition that can be overruled by normative reason in any specific case. Moreover, that fact that a status-quo orientation is logically tenable does not imply that it is imperative. Perhaps, an equally logically tenable case can be made for a radical or idealist disposition (Brennan and Hamlin, 2016[a], 367; Taylor, 2013; see also Clarke, 2017). Nevertheless, in politics one may plausibly proceed on the basis of a general, rebuttable presumption in favor of the given. ${ }^{5}$ Following this view, the burden of proof in politics rests on the progressive innovator (as well as the nostalgic who wishes to re-establish a status quo ante [cf. Huntington, 1957, p. 460]). Considerations (2.1), (2.5), (2.6) and the idea of strategic adherence are orthogonal to individual dispositions. They show that every one of us should, under certain conditions, refrain from forcing institutional change whatever our particular ideological views are. People of progressive self-understanding should sidetrack emancipatory aspirations just as nostalgics should put their reactionary visions on hold if there is no room for improvement (lack of alternatives, lack of feasibility), if (and as long as) the existing arrangement is democratically authorized, and if the acceptance of an imperfect institution is the only way to prevent greater evil.

\section{Conservation as a mode of political action}

Now suppose that we find ourselves in a situation in which we have actually reached the conclusion that the best thing to do is to abstain from changing some existing institution. What are the practical consequences of this conclusion? What needs to be done to leave things as they are? Must anything be done at all? This section argues that quietism isn't the conservator's recipe for success. Bringing about institutional non-change requires positive political action.

\subsection{Actor interference and designed institutional change}

5 Note that this is not to deny that the precise content of the 'given' may often be in dispute. I will touch upon this issue in Section 4.4. 
It seems quite reasonable to expect that an established institution persists unchanged as long as political actors don't abolish or reform it. If this were generally the case, conservation would result from political inaction. And we would have to qualify this picture only marginally by the non-ideal theoretical consideration that there is always someone who pushes for change even if, all things considered, it would be the best to leave things as they are. Instead of staying entirely clear of politics, the key strategy for achieving institutional non-change would accordingly be to oppose the plans of starry-eyed idealists. Lord Derby comes close to epitomizing this understanding. He preferred to be leader of the opposition over the office of Prime Minister because he hoped that this would more effectively allow him to dissuade government from 'doing things' (Charmly, 1996, p. 2).

Notably, this 'stagnatist' view is frequently presupposed in contemporary scholarship on (the justification of) status quo biases. Arguments that emphasize transition costs and the problems related with their calculation ([2a] and [2b]) typically establish that the value of an existing institution is outbalanced if the (basic) value of an alternative arrangement minus transition costs exceeds the (basic) value of the established institution plus path dependency benefits (and existence value) (e.g. O'Hara, 2011, p. 88; but see O'Hara, 2016, p. 429). Hence, it is assumed that the established institution would continue to have the same overall value as time goes on unless it is replaced or substantially modified, which in turn means that institutions remain unchanged in the absence of direct actor interference. Corroborating this observation, Beyer (2005, p. 12; see also Thelen, 1999) argues that path dependency theory in general and, in particular, historical institutionalism, consider institutions to be eo ipso enduring entities. G.A. Cohen's (2013) discussion of existence value (2c) is another case in point. He illustrates his argument with a discussion about whether Oxford's All Souls College should be transformed into a less insular institution. He admits that opening the college to outside sources of funding and short-term research associates without college affiliation might realize its main purposethe promotion of research—-better than the current arrangement. Nevertheless, he rejects calls for change on the basis that this change would bring a loss of the distinctive value that the college embodies as a valuable social creation, and because it would affect the college's identity as an independent institution. As long as no active steps towards reform are undertaken by the college administration, Cohen therefore suggests at this point, All Soul's identity persists unchanged. In another example, Cohen informs us 
about the horrors he has when only considering the possibility that his fourty-four year-old eraser pencil could be replaced, regardless of whether the substitute would be a brand-new eraser pencil or one that is as old and worn as his own. Here, Cohen (2013, p. 167) not only suggests that his eraser persists unchanged as long as it isn't replaced, but also that it has retained its identity for half a century despite the wear and tear caused by usage.

However, towards the end of his paper Cohen $(2013$, p. 169, 172) notes that it will often be necessary to proactively do something to achieve the goal of keeping things as they are. The next section elaborates on this qualification and shows how institutions can become transformed even if there is no one trying to reform or abolish it. ${ }^{6}$

\subsection{Environmental developments and accidental institutional change}

Institutions may not change by themselves, but they neither exist in a vacuum. The stagnatist understanding of conservation fails to take the context in which institutions find themselves into account because changes in this context may accidentally affect their identity. As stated in the section on transition costs (2a), the meaning and working of an institution is contingent upon the meaning and working of interdependent (other) institutions and the political landscape more generally. If this context is transformed, the institution might cease to work properly or start doing some work it was not designed for. Furthermore, cultural and moral change, technological and scientific innovation or economic and ecological developments may also constitute 'external shocks' that threaten an institution's continued existence. For simplicity, I will speak of 'environmental developments' to refer to such changes of an institution's context that have the effect, designed by no one, of transforming the institution itself. ${ }^{7}$

${ }^{6}$ Another qualification that Cohen adds holds that, strictly speaking, positive action cannot prevent but only mitigate decay. The overall view proposed in this paper is that conservation as a mode of political action can actually prevent institutional decay, even though it cannot guarantee the numerical identity of an institution over time.

7 In addition to this, certain dynamics internal to institutions might erode the conditions for their own survival. Think, for instance, of Schumpeter's (1975) point about the self-destructive tendency of 
All Souls College, to pick up on Cohen's example, is 'protected by countless societal conventions, legal structures that allow it autonomy, preserve its assets from seizure or despoliation' (David quoted from Cohen, 2007, p. 8 fn. 11). Therefore, the college's insular character could be mitigated not only by internal reforms but also by external legal change. Mass media and digitalization, to give another example, arguably redefined the functions of free speech rather radically (O'Hara, 2011, p. 61). And the gun laws in Svalbard, which establish a duty to carry arms outside settlements would certainly take on a different meaning should climate change exacerbate in such a way as to destroy the natural habitat of polar bears. Under conditions of environmental developments conservation becomes a task. The impact of relevant environmental developments must in some way be diverted if accidental institutional change is to be prevented.

An unpromising strategy to go about the task of conservation is to try to prevent environmental developments in the first place. One would have to dissuade policy makers from 'doing things', reverse cultural, economic, etc. developments, and uninvent inventions, all of which suggests that this desire to bring history to a halt is a hopeless endeavour. 'Change', Burke (2005, p. 302) remarked in a letter to Sir Hercules Langrishe, 'is the most powerful law of nature'. The context of institutions permanently undergoes transformations, which potentially affects these institutions. Nevertheless, Burke seems to have believed that institutions could in some meaningful way be kept unchanged. His famous dictum 'a state without the means of some change is without the means for its conservation' (Burke, 2009, p. 21) suggests that there is an alternative strategy for conservation under conditions of changing circumstances. Rephrased in the language used in this paper, Burke's dictum claims that accidental institutional transformation caused by environmental developments can be averted by intentionally reforming the institution in question itself. The following section tries to make sense of this prima facie paradoxical idea.

\section{Resolving Burke's conservation 'paradox'}

capitalism. I bracket such forms of accidental change out of the present discussion as they would require a more detailed analysis than can be provided here. 
Burke himself doesn't do much to resolve what we might call the paradox of conservation, i.e. the idea that institutional change is a necessary means to achieve institutional non-change. He argues that order maintenance must be the first priority of government, and that the order can be maintained only if statespersons are prepared to undertake reforms. Yet the examples horticultural analogies he provides aren't clear enough to positively explain of what kind such reforms would have to be. He tells us, for instance, that statespersons mustn't follow the lead of bad gardeners who graft shoots onto a tree that are 'alien to the nature of the plant' (Burke, 2009, pp. 31, 33, 157-8). Translated into political practice, this means that the social engineering of rationalist philosophes fails to abide by the rules of good governance because it aims at institutional innovation. Statespersons who follow the lead of good gardeners instead aim at organic growth, in Burke's view, but the goal of organic growth isn't the same as the goal of institutional non-change. Instead it reflects his third principle of good governance, namely the 'principle of improvement', which may motivate quite different courses of action than the other two principles, namely the 'principle of transmission' and the 'principle of conservation' (Burke, 2009, p. 33). ${ }^{8}$ Most to the point is Burke's insertion that fixed rules can be reconciled with occasional deviations (Burke, 2009, p. 21). In cases of 'extreme emergency', even a 'sacred' institution such as the hereditary principle can be applied differently, he argues. The change, then, would have to be confined to the 'peccant part only; to the part which produced the necessary deviation.' But apart from the fact that it isn't clear whether Burke, here, thinks that environmental developments create the need for a political action aimed at conservation, he makes clear that any deviation would have to be a temporary exception, whereas environmental developments such as scientific or technological innovation may change the context of an institution forever. And while Burke's also discussion of the Glorious Revolution in

\footnotetext{
8 Note that the discussions of good and bad kinds of change (e.g. organic vs. artificial, intimated vs. rationally conceived, piecemeal vs. large-scale, slow vs. fast, reversible vs. irreversible, demanddriven vs. supply-driven change; Oakeshott, 1991b; O’Hara, 2011, p. 74; Quinton, 197, pp. 16-17) that are typically offered by analyses of conservative political theory don't resolve the conservation paradox. These distinctions are usually expressions of a desire to minimize risk and keep the society on a steady, if slow, course towards growth or even progress.
} 
particular, as well as of hierarchy and religion in general can be read as revolving around the question of institutional non-change, Burke's Reflections are certainly stronger in terms of judgment and practical know-how than conceptual analysis. ${ }^{9}$

\subsection{Tomasi di Lampedusa: Faking real change}

Tomasi di Lampedusa's The Leopard (2007) promises to enhance our understanding of Burke's paradox and possible solutions. Scholars of conservatism at least have often professed that the novel's leitmotif ('If we want things to stay as they are, things will have to change', Tomasi di Lampedusa, 2007, p. 28) expresses the same prima facie paradoxical strategy of conservation as Burke's dictum (Alford and Hunt, 1988, p. 1; Hill, 2011, p. 86; Robin, 2010, pp. 372, 2015; Skorupski, 2015, pp. 401, 421 fn1).

However, a close reading reveals significant differences. Tomasi di Lampedusa offers two interpretations of the idea that things must change to stay the same. The interpretation offered by Tancredi, the character who introduces the reader to the (seeming) paradox, maintains that real change can be averted by proactively enforcing petty change and deceiving people into thinking that real change has happened. Liberal revolutionaries, he contends, will be allured from abolishing the hierarchical society and establishing a republic if they are only offered a different king. ${ }^{10}$ The second interpretation is offered by Don Fabrizio, the novel's main character. The revolutionaries, he predicts, will indeed bring a new king to power, kill a few people and even substitute the aristocrats with the bourgeoisie as ruling class. However, none of this qualifies as real change in his view because life's general misery

9 If it weren't for the present purposes, the 'unspoken wisdom' character of Burke's approach could of course be considered a strength rather than a weakness (e.g. O’Hear, 1998, section 1).

10 [Don Fabrizio:] 'A Falconeri should be with us, for the King.' Tancredi's eyes began smiling again. 'For the King, yes, of course. But which King?' The lad had one of those sudden serious moods which made him so mysterious and so endearing. 'Unless we ourselves take a hand now, they'll foist a republic on us. If we want things to stay as they are, things will have to change.' (Tomasi di Lampedusa, 2007, p. 28). 
will persist. ${ }^{11}$ Hence, Don Fabrizio champions what Albert O. Hirschman called the 'futility thesis': 'the attempt at change is abortive $[\ldots]$ in one way or another any change is, was, or will be largely surface, façade, cosmetic, hence illusory, as the "deep" structures of society remain wholly untouched" (Hirschman, 1991, p. 43). Politics, Don Fabrizio thinks to himself accordingly, is a chimera; it 'claim[s] to influence the course of fate that [is] actually flowing along on its own in another valley' (Tomasi di Lampedusa, 2007, p. 31). In short, whereas the first interpretation in The Leopard establishes that fake change satisfies idealists' desire for real change, the second claims that things will stay what they are however hard people to try to transform them into something else. While both interpretations establish a meaningful understanding of sameness over time, only the first articulates a political strategy. And neither of them reflects about the possibility of accidental institutional transformation resulting from environmental developments.

\subsection{Huntington: Changing secondary elements}

Samuel P. Huntington's 'Conservatism as an Ideology', written a year before The Leopard was published, also mentions Burke's paradox. Huntington depicts conservatism as a situational ideology that lacks a substantive ideal and that defends the status quo while opposing change if the established order is perceived to be exposed to danger. After rejecting other definitions of conservatism, he remarks en passant that 'in order to preserve the fundamental elements of society, it may be necessary to acquiesce in change on secondary issues' (1957, p. 455). Applied to individual legal institutions, Huntington's remark implies that an institution will be conserved as long as its fundamental elements, or essence, is preserved (remains unchanged), even if (some of) its secondary elements change. He goes beyond other scholars who construed conservatism as a situational ideology that lacks a substantive ideal by considering change on secondary elements a means for the preservation of primary elements. ${ }^{12}$

11 [Don Fabrizio:] 'What will happen then? Oh, well. Just negotiations punctuated by little harmless shooting, then all will be the same though all will be changed' (Tomasi di Lampedusa, 2007, p. 33).

12 Compare Huntington's quote with, for instance, Tännsjö's (1990, p. 47) considerations or the following statement by Wilson (1941, p. 33): 'Conservatism is not necessarily a defense of the status 
However, just like Tancredi, Huntington locates the potential challenges for existing arrangements in the activism of other political actors. Moreover, he elaborates neither on the question of why and how change of secondary elements helps to preserve the fundamental elements of a polity, nor what elements of a polity are fundamental and which secondary.

Nevertheless, Huntington's distinction between change on fundamental or change on secondary elements is worthy of discussion. With this distinction, Huntington presumably alludes to Aristotle's considerations about Theseus' paradox, where a ship's planks are piece-by-piece replaced until the ship is completely redone, and the question arises whether the renovated ship is numerically identical with the original one. In Hobbes' version of the paradox, the dismantled original planks are moreover used to build another ship. The puzzling result is that it isn't clear which of the two, if any, is the original ship of Theseus (Hobbes, De Corpore, II. 11, 7). Formalists and materialists have given opposite answers, arguing either that the continuity of form overrules the continuity of matter or that the reverse is true. Because of this impasse contemporary philosophers of nature discussing the persistence of material objects over time have turned to developing theories that do not require a hierarchization of properties of material things (in particular: endurantism exdurantism, and perdurantism) ${ }^{13}$ However, this doesn't mean that theorists of politics cannot make a plausible distinction between fundamental and secondary institutional components. Institutions are instruments of civil association after all, and their instrumentality requires a prioritization of certain institutional components over others. ${ }^{14}$

Among institutional components, it is common to distinguish between an institution's structure (i.e. organizational components, rules and roles), culture (i.e. underpinning or embodied values, conventions, norms and manifestations of symbolic representation), mechanisms (i.e. procedures and apparatus of sanctions and rewards) and outcomes (i.e. the social products of its manifest and latent functions). Quite

quo; in no case could it be a defense of everything as it is, but it is a defense of primary elements in the social structure, with concessions made on secondary problems'.

13 For an overview, see Haslanger and Kurtz (2006).

14 See Johannson (2006) for a detailed analogous argument about the persistence of organizations over time. 
obviously, policy makers must compare the outcomes of an established institution with conceivable alternatives to decide whether it ought to be conserved or replaced, and an institution's structure, culture and mechanisms are instrumental to bringing about its outcomes. Hence, an institution's outcomes are primary to its structure, culture and mechanisms from the viewpoint of public reason. ${ }^{15}$ However, as institutional outcomes can never be fully known with certainty (recall sections [a] and [b]), it is more accurate to say that an institution's mandate is fundamental to the institution's identity. The institutional mandate refers not to what an institution actually does, but what it is meant to do, i.e. the social outcomes that the institution is meant to deliver, or, in Popper's (1972, p. 133) words, its prima facie social functions and purposes.

On this basis, we can specify Huntington's solution of the conservation paradox by saying that reforms of an institution's mandate constitute real changes and as such undermine the institution's continued existence over time while reforms of its structure, culture or mechanisms do not. Following this line of thought, one might for instance argue, as does Wilson (1941, p. 33), that the institution of private property can be maintained even if its specifically instantiating system of relations of production is abandoned. For the conservation of the institution of marriage, to give a second example, it would appear to be crucial that it still encourages reproduction, child-raising, economic risk-sharing; that it fosters committed relationships among individuals, enhances personal security through a system of mutual care for the young and old, and perhaps domesticates sexual affairs; but it would be negligible whether priests or registrars solemnize marriage.

\subsection{Counterbalancing environmental change}

The previous subsection only explained why institutions can survive certain changes. To formally resolve Burke's paradox of conservation we still need to show how and under what conditions reforms of an institution's structure, culture or mechanisms help to preserve its mandate. To accomplish this

15 A related way of putting this is to say that the institutional components of structure, culture and mechanisms contingently instantiate the institution, which, ontologically speaking, exists prior to its contingent instantiation (MacCormick and Weinberger, 1986, p. 54). 
task, we must integrate the variable of environmental developments. With this, we can understand conservation as a mode of political action that adapts institutions to make them suitable for their prima facie purposes and functions under novel circumstances. Thus, political conservation can be likened to the interpretive re-contextualization of historical texts: just as a contemporary reader of a historical text must counterbalance linguistic change to avoid anachronisms, so must legislators reform the instantiation of an institution in accordance with changing circumstances: an institution can be conserved, if its mandate is being preserved (i.e. remains unchanged) by means of changing the institution's structure, culture or mechanisms in such a way as to counterbalance extra-institutional developments.

This understanding helps to formally resolve the paradox of conservation, or at least to show that it is a seeming paradox only. If no circumstances between $t$ and $t+1$ alter, stagnatists and Burkeans recommend the same course of action: political inaction. However, if relevant circumstances alter, the former must counter technological, economic, etc. developments to prevent accidental institutional change. The latter, in contrast, will try to counterbalance environmental developments to keep the institution in step with the times.

The logic can be illustrated by taking up the hypothetical Svalbard case. Imagine that polar bears really go extinct in Svalbard. The prima facie social function and purpose of the gun laws (to wit: personal safety) would be most authentically preserved by prohibiting, rather than requiring, the carrying of arms outside settlements. Drastic environmental developments may require us to turn an institution upside down to conserve it and prevent its accidental transformation into something else. The non-hypothetical case of marriage also illustrates the logic that reform facilitates the preservation of institutional mandates. It is after all fair to say that since the 1950s a number of relevant environmental developments have occurred that affect the persistence of the institution of marriage. To name but a few of these changes: the nutritional quality of infant formulas has immensely improved, such that breastfeeding is no longer strictly necessary; homosexuality isn't any more considered to be abnormal by most segments of Western societies; children of same-sex couples do not seem to become systematically the victim of homophobic social ostracism, etc.; strictly speaking, even heterosexual intercourse is no longer a necessary condition for fertilization. Thus, due to bio-medical innovation and change of social norms 
an actualization of the institution of marriage may indeed have become exigent. The institution's prima facie social functions and purposes (such as encouraging reproduction, child-raising, economic risksharing, fostering committed relationships among individuals, enhancing security through a system of mutual care for the young and old, and domesticating sexual affairs) today can be equally instantiated in couples of different sex and same-sex couples. Referring to the principle of non-discrimination is one (a progressive, non-Burkean) way to justify the same-sex inclusive regulation of marriage; saying that we don't want this institution to change is another. ${ }^{16}$

\subsection{Disputes about conservation}

Whether the context of some institutions has changed significantly enough to threaten its persistence is a question that is appropriately answered neither by theorists nor practitioners of politics, but instead by scientists. Experts are best suited after all to empirically assess whether and which economic, technological, ecological, etc. developments have taken place. Thus, conservation as a mode of political action entails a technocratic dimension even though proper political disputes may arise when it comes to the question of whether, which and to what extent changing circumstances have a potential to affect existing institutions. Yet the crux of the matter lies elsewhere, namely in the identification of institutional mandates, and a brief comparison with the partially analogous challenge in constitutional interpretation elucidates how likely it is that intricate controversies will arise.

In constitutional interpretation, there are two major points of contention. First, a lot of controversy revolves around the question of whether constitutions are living traditions. Those who think they are basically demand that the prima facie social functions and purposes (i.e. the 'mandate') of constitutional articles be adapted (by the judiciary) to changing circumstances. This controversy is of secondary importance for the present task. It is beyond question that institutional change is often what legislators should seek but when it isn't, redefining mandates doesn't facilitate conservation. The second issue that provokes disagreement in constitutional interpretation concerns the method by which constitutional

16 For a detailed presentation of such a 'traditionalist' case for same-sex marriage, see [Note suppressed to ensure anonymity]. 
mandates are identified. This problem does apply to the identification of institutional mandates, even a forteriori. The problem of method is even more complicated in the case of institutions than constitutions as tricky questions arise when it comes to discerning the relevant body of source material. Parliamentary proceedings might be as important as legal documents for a reconstruction of institutional mandates, and which to include will depend not only upon methodological choices. ${ }^{17}$ Also, disputes may arise about whether an earlier reform of the institution in question had effectively redefined the institutional mandate instead of merely adapting the institutional structure, culture or mechanisms. The present article can only bring up the questions of method, sources and midstream temporal flux in an institution's mandate rather than providing answers for them. ${ }^{18}$ Yet posing these questions at least makes clear that intricate political disputes may arise even if the agreed policy goal is to leave everything as it is.

\section{Implications and outlook}

The first part of this paper listed six considerations that may lead us in a given situation to the conclusion that the best thing to do is to prevent institutional change. It also showed that no commitment to a specific ideology is necessary to reach that conclusion. Conservation as a mode of political action may, but need not be, motivated by conservative ideology, not even by a status-quo orientation. The second part argued that extra-institutional developments such as technological and scientific innovation, ecological degradation or economic globalization can accidentally transform the meaning and functioning of institutions. Hopes to conserve an institution and prevent its decay, I argued, are therefore likely to be frustrated by political quietism. Even if relevant circumstances do not change, political conservation will under non-ideal theoretical conditions at least require to dissuade other political actors in one way or another from undertaking institutional transformation. As soon as relevant environmental

${ }^{17}$ Methods that use a broader body of sources might be confronted with the 'baseline problem', which also haunts ecological restoration efforts.

18 A particularly promising method might be found in Axel Honneth's (2014, pp. 1-12) 'normative reconstruction'. 
developments take place, however, conservation becomes a proactive mode of political action that must resolve Burke's paradox according to change is a necessary means to achieve non-change. Table 1 summarizes these strategies of political conservation.

\section{Table 1: Strategies of political conservation}

\begin{tabular}{|l|l|}
\hline Challenge to institution & Political strategy \\
\hline None & Quietism (Don Fabrizio) \\
\hline Designed reform or innovation & Dissuasion (Derby, Huntington) \\
\hline (caused by legislators or activists) & Faking real change (Tancredi) \\
\hline Accidental change & Renovative reformism (Burke) \\
\hline (caused by environmental developments) & \\
\hline
\end{tabular}

The third part developed a formal solution to Burke's paradox by construing conservation as a reformism that aims at preserving an institution's mandate by modifying elements of its structure, culture or mechanisms in correspondence with environmental developments. The forth part showed that political conflicts are likely to even among persons who are equally interested in leaving things as they are. Political conservation, therefore, really is a political mode of action. Its peculiarity, compared with progressive (or reactionary) kinds of reformism is that reforms are undertaken for the sake of renovation instead of innovation (or restauration).

A straightforward implication of the presented argument concerns our understanding of interventions in academic and public discourse on politics. Reformism, calls for institutional transformation, even advocacy for radical change is not necessarily a sign of a progressive or reactionary politics; it can also be a non-emancipatory and non-nostalgic reflex to changing circumstances. We should therefore make more transparent whether our recommendations for institutional change are meant to emancipate us from the normativity inherent in already existing arrangements or adapt these arrangements to changing circumstances - or, however, to settle a political controversy over institutional mandates under dispute or in flux. 
A second implication concerns the reasons for not changing some established institution. The rebuttable presumption in favor of the given is weakened, though not invalidated, by the fact that conservation comes with costs of its own. Whereas institutional innovation incurs transition costs, institutional conservation incurs maintenance costs. Moreover, their amount may not be known with certainty in advance. There is a risk that political actors misjudge the relevance of environmental developments as well as a risk that reform measures peter out or cause unwanted consequences. Furthermore, the fact that the task of conservation often requires renovative reformism means that maintenance costs will be particularly high if citizens identify not only with an institution's mandate, but also with that institution's contingent instantiation. As argued before, the extinction of polar bears in Svalbard would, should it happen, require transforming the duty to carry arms outside settlements into a restrictive gun control law to guarantee personal safety. But Svalbardians may then already have grown so fond of their guns that they consider the possession of arms relevant for their central organizing self-conception. Conservative dispositions and political conservationism can come to pull in opposite directions.

The main goal of this paper has been to improve our theoretical understanding of the justification and operation of a mode of political action to which we are thrown back if improvement of the status quo is not an available option. This mode of political action is not, to reaffirm, a project of the Right. The French Revolutionaries knew this. They were aware that any act of founding is futile unless provisions are made to stabilize the new foundation, and it therefore doesn't come as a surprise that they were the first to use the term 'conservative' as a political concept and claim the title of being conservative for themselves long before the enemies of the ideas of the French Revolution did. ${ }^{19}$ Today, conservation as a mode of political action is even more relevant than back then. Apart from the already

19 Already in 1789 , the goal was articulated to establish a 'constitution conservatrice'. Napoleon's famous declaration from 19 Brumaire 1799 'Les ideés conservatrices, tutélaires, 'libérales' sont rentrées dans leur droit par la dispersion des factieux qui opprimaient les Conseils' reflects in a report of 18 Thermidor of year IV that characterizes government as a 'gouvernement tutélaire et conservateur.' (quotations from Vierhaus, 1982, p. 537). 
mentioned subjective disbelief in progress among many citizens, a significant number of institutions in our liberal democracies appear to be empirically legitimate, linked with the central organizing selfconception of citizens, costly to replace, normatively justifiable or likely to stand a chance of being replaced in the democratic process only by normatively inferior alternatives. In addition to this, the world around institutions is changing in unprecedented quality and pace (Scheuermann and Rosa, 2008). Freedom of speech and privacy, as we know them, are affected by processes of digitalization and the arrival of Islamist terrorism in Western metropoleis; the welfare state totters in the face of demographic aging trends, migration waves, increased mobility, and economic globalization; technocratic closure and populism reflexes challenge the (multi-)party model of representation (Caramani, 2017); and all of these environmental developments put liberal democracy as we know it under pressure. Robert A. Dahl's (1989, p. 319) diagnosis that democracy will not stay the same unless it undergoes a third transformation appears to be more topical than ever.

Ironically, perhaps, the Left should have the greatest objective interest in a theory of conservation. Despite its progressive self-understanding, many on the Left appear to be afraid that basically any further development will diminish the past achievements of the liberal-democratic order, or even that institutional decline has already occurred (e.g. Crouch, 2004). According to Turner, this tendency becomes particularly clear when considering the European Left's relationship to the welfare state:

For the European Left, any alteration in the arrangement of the welfare state, its benefits, its actual practices, is experienced not as opportunity or even as opportunity mixed with risk, but as loss of the familiar. And these societies are increasingly present oriented and concerned with the enjoyment of the present, which is more and more understood as the best of all possible worlds. The European Left has no grand project. It is committed instead to resistance, resistance to what it characterizes as neo-liberalism and the savage inequalities of feral capitalism, and, on a practical and less rhetorical level to the specific rights that are enjoyed by citizens of a pervasive welfare state. (Turner, 2010, p. 213)

If it turned out that we are overburdened even with the seemingly moderate task of preventing things from getting worse, would we have to consider if this provides us with an indirect justification for a progressive bias in politics? Might the acceleration and the complexity of the world serve as a 
vindication for an adventurous mode of political action that promotes changes designed to implement institutional innovation even if the net outcome of innovation is unlikely to be superior to the existing state of affairs? One of George Bernard Shaw's (1957, p. 260) maxims for revolutionists gets right to the heart of this idea:

The reasonable man adapts himself to the world.

The unreasonable one persists in trying to adapt the world to himself.

Therefore all progress depends on the unreasonable man.

However, not only innovation but also conservation can be a vital source of progress (see also Graham and Thrift, 2007). Attempts to prevent institutional decay, even if perfectly justified in the situation that obtains, may not be crowned with success. Conservation attempts may often only imperfectly manage to actualize an institution due to the tricky task of discerning the relevant environmental developments in a highly complex and confusing world. Already the unintended consequences of such imperfect conservation efforts can, as any unintended consequence, turn out to be benign rather than malign. On top of that, however, the incessant task of actualization in a permanently changing context facilitates a before-and-after comparison between the institutional mandate and its outcomes, and thus serves as a feedback loop of trial-and-error experimentation that may well enable us to advance in the long run. Pace Shaw, not all progress is created by unreasonable people.

\section{References}

Alford, J., \& Hunt, K. eds. (1988). Europe in the Western Alliance. London Macmillan.

Beckstein, M. (2015). What Does It Take to be a True Conservative, Global Discourse, 5, 4-21.

Berlin, I. (1990). The Pursuit of the Ideal. In: The Crooked Timber of Humanity. London: John Murray, $1-19$.

Beyer, J. (2005). Pfadabhängigkeit ist nicht gleich Pfadabhängigkeit! Wider den impliziten Konservatismus eines gängigen Konzepts. Zeitschrift für Soziologie 34, 5-21.

Bregman, R. (2016). Utopia for Realists. The Case for a Universal Basic Income, Open Borders, and a 15-hours Workweek. Amsterdam: The Correspondent. 
Brennan, G., \& Hamlin, A. (2004). Analytic Conservatism. British Journal of Political Science 34, 675691.

(2016a). Conservative Value. The Monist 99, 336-351.

(2016b). Practical Conservatism. The Monist 99, 352-71.

Burke, E. (2005). Letter to Sir Hercules Langrishe, on the Subject of the Roman Catholics of Ireland. In: The Works of the Right Honourable Edmund Burke. Project Gutenberg. London: John C. Nimmo, 4:241-306.

- (2009). Reflections on the Revolution in France. Oxford; New York: Oxford University Press.

Caramani, D. (2017). Will vs. Reason: The Populist and Technocratic Forms of Political Representation and Their Critique of Party Government. American Political Science Review 111, 54-67.

Charmley, J. (1996). A History of Conservative Politics 1900-1996. Basingstoke: Macmillan.

Clarke, S. (2017). A prospect theory approach to understanding conservatism, Philosophia, 45, 551568.

Cohen, G.A. (2007). A Truth in Conservatism: Rescuing Conservatism From the Conservatives. Available online at http://www.bookforum.com/blog/1551. Visited 16 May 2016.

(2013). Rescuing Conservatism: A Defense of Existing Value. In: Otsuka, M. ed. Finding

Oneself in the Other. Princeton, N.J: Princeton University Press, 143-174.

Crouch, C. (2004). Post-democracy. Cambridge: Polity.

Dahl, R.A. (1989). Democracy and Its Critics. New Haven: Yale University Press.

Freeden, M. (1996). Ideologies and Political Theory: A Conceptual Approach. Oxford: Oxford University Press.

Graham, S. and Thrift, N. (2007). Out of Order: Understanding Repair and Maintenance. Theory, Culture \& Society 24, 1-25.

Habermas, J. (1986). The New Obscurity: The Crisis of the Welfare State and the Exhaustion of Utopian Energies. Translated by P. Jacobs. Philosophy and Social Criticism 11, 1-18.

Haslanger, S., \& Kurtz, R.M. eds. (2006). Persistence. Contemporary Readings. Cambridge, Mass.: MIT Press. 
Heidegger, M. (1971). Building, Dwelling, Thinking. In: Poetry, Language, Thought. Trans. A. Hofstadter. New York: Harper and Row.

Hill, C. (2011). Changing the World? The Problem of Action in International Politics. Cambridge Review of International Affairs 24, 81-98.

Hirschman, A.O. (1991). The Rhetoric of Reaction: Perversity, Futility, Jeopardy. Cambridge, Mass.: Harvard University Press.

Honneth, A. (2014). Freedom's Right: The Social Foundations of Democratic Life. New York: Columbia University Press.

Huntington, S.P. (1957). Conservatism as an Ideology. The American Political Science Review 51, 454 473.

(1965). Political Development and Political Decay. World Politics 17, 386-430.

Ipsos MORI. 2014. People in Western Countries Are Pessimistic About Future for Young People. Ipsos MORI Global Trends Survey, accessed 20 October 2016. Available online at: https://www.ipsosmori.com/researchpublications/researcharchive/3369/People-in-western-countries-pessimisticabout-future-for-young-people.aspx

Ipsos MORI (2017) 'Megatrends: Long-term Trends Shaping the World in 2017 and_Beyond: 2. The rise and rise of tradition,' accessed 30 November 2017. Available online at: https://www.ipsosglobaltrends.com/megatrends-long-term-trends-shaping-the-worldin-2017-andbeyond/.

Irigaray, L. (1992). Ethics of Sexual Difference. Ithaca: Cornell University Press.

Johansson, I. (2006). Identity Puzzles and Supervenient Identities. Metaphysica 7, 7-33.

Kriele, M. (1979). Recht und praktische Vernunft. Göttingen: Vandenhoeck\&Ruprecht.

MacCormick, N., \& Weinberger, O. (1986). An Institutional Theory of Law. New Approaches to Legal Positivism. Dordrecht: Kluwer Academic Publishers.

Muller, J.Z. (1997). Conservatism: An Anthology of Social and Political Thought. Princeton, N.J.: Princeton University Press.

Nebel, J.M. (2015). Status Quo Bias, Rationality, and Conservatism about Value. Ethics 125, 449-76.

O’Hara, K. (2011). Conservatism. London: Reaktion Books. 
(2016). Conservatism, Epistemology and Value. The Monist 99, 423-40.

Oakeshott, M. (1991a). On Being Conservative. In: Rationalism in Politics and Other Essays. Indianapolis: Liberty Fund, 407-437.

(1991b). Political Education. In: Rationalism in Politics and Other Essays. Indianapolis: Liberty Fund, 43-69.

. (1991c). Rationalism in Politics. In Rationalism in Politics and Other Essays Indianapolis: Liberty Fund, 5-42.

_. (1996). The Politics of Faith and the Politics of Scepticism. New Haven, Conn.: Yale University Press.

O’Hear, A. (1998). Conservatism. In Routledge Encyclopedia of Philosophy, ed. by. E. Craig. London: Routledge.

O’Neil, M., \& Williamson, T. eds. (2012). Property-owning Democracy: Rawls and Beyond. Malden, MA: Wiley-Blackwell.

Pierson, P. (2000). Increasing Returns, Path Dependence, and the Study of Politics. American Political Science Review 94, 251-67.

Popper, K.R. (1972). Towards a Rational Theory of Tradition. In Conjectures and Refutations. The Growth of Scientific Knowledge, $4^{\text {th }}$ ed. London: Routledge and Kegan Paul, 120-35.

Quinton, A. (1978). The Politics of Imperfection. London and Boston: Faber and Faber.

Robin, C. (2010). You Say You Want a Counterrevolution. Well, You Know, We All Want to Change the World. In Greg Grandin and Gilbert M. Joseph. eds. A Century of Revolution. Insurgent and Counterinsurgent Violence During Latin America's Long Cold War, 371-380. Durham and London: Duke University Press.

Robin, C. (2015). We Have the Left and Right all Wrong: The Real Story of the Politics of Nostalgia and Tradition. The Economist, August 2, 2015. Online at: http://www.salon.com/2015/08/02/we have the left and right all wrong the real story of the politics of nostalgia and tradition/. Accessed: March 24, 2017.

Ruiter, D.W. (2001). Legal Institutions. Dordrecht: Springer. 
Scheuermann, W.E., \& Rosa, H. eds. (2008). High-Speed Society: Social Accelleration, Power, and Modernity. University Park: Penn State University Press.

Schumpeter, J.A. (1975). Capitalism, Socialism, and Democracy. New York: Harper Perennial.

Shaw, G.B. (1957). Man and Superman. London: Penguin.

Skorupski, J. (2015). The Conservative Critique of Liberalism. In Steven Wall, ed. The Cambridge Companion to Liberalism, 401-22. Cambridge: Cambridge University Press.

Smith, S.B. (2016). Modernity and its Discontents. The Making and Unmaking the Bourgeois from Machiavelli to Bellow. New Haven and London: Yale University Press.

Sunstein, C.R. (2005). Laws of Fear: Beyond the Precautionary Principle. Cambridge: Cambridge University Press.

Tännsjö, T. (1990). Conservatism for Our Time. London/New York: Routledge.

Taylor, B. (2013). Analytic Radicalism. Constitutional Political Econonmy 24, 166-72.

Taylor, P., Funk, C., \& Craighill, P. (2006). Once Again, the Future Ain't What It Used to Be. Washington: Pew Research Center, 2006. Accessed 20 October 2016. Available online at: http://www.pewsocialtrends.org/2006/05/02/once-again-the-future-aint-what-it-used-to-be/

Thelen, K. (1999). Historical Institutionalism in Comparative Politics. Annual Review of Political Science 2: 369-404.

Tomasi di Lampedusa, G. (2007). The Leopard. New York: Random House.

Turner, S.P. (2010). The Conservative Disposition and the Precautionary Principle. In: Abel C (ed.) The Meanings of Michael Oakeshott's Conservatism. Exeter: Imprint Academics, 204-217.

Vierhaus, R. (1982). Konservativ, Konservatismus. In: Brunner, O., W. Conze and R. Koselleck, eds. Geschichtliche Grundbegriffe: Historisches Lexikon zur politisch-sozialen Sprache in Deutschland; vol. 3, 531-65. Stuttgart: Klett-Cotta.

Wall, S. (2015). Political Morality and the Authority of Tradition. Journal of Political Philosophy, doi: 10.1111/jopp.12058, 1-25.

Williams, M.C. (2005). The Realist Tradition and the Limits of International Relations. Cambridge: Cambridge University Press.

Wilson, F.G. (1941). A Theory of Conservatism. American Political Science Review 35, 29-43. 
Young I.M. (1997). Intersecting Voices: Dilemmas of Gender, Political Philosophy, and Policy. Princeton. Princeton University Press. 